\title{
Audit of screening programme for congenital hypothyroidism in Scotland 1979-93
}

\author{
M Ray, T M Muir, G D Murray, R Kennedy, R W A Girdwood, M D C Donaldson
}

\begin{abstract}
Objective-To evaluate the efficiency of the screening programme for congenital hypothyroidism in Scotland and to determine the outcome in the cohort of children with positive testing for thyroid stimulating hormone (TSH).

Design-Establishment of comprehensive database for all Scottish infants with high TSH, detected on Guthrie screening. Subjects-344 infants born between August 1979 and December 1993 with TSH greater than $40 \mathrm{mU} / 1$ on initial Guthrie, or 15-40 mU/1 on repeat Guthrie.
\end{abstract}

Main outcome measures-Ages at time of: (a) Guthrie collection, (b) notification of positive result by laboratory, and (c) start of treatment; audit of late diagnosis/ missed cases; categorisation of positive cases into definite and probable congenital hypothyroidism, transient TSH elevation, and uncertain status; educational status of children with definite and probable congenital hypothyroidism.

Results-344 positive cases were categorised as having definite (224) and probable (11) congenital hypothyroidism, transient TSH elevation (88), and status uncertain (21). The overall incidence of definite/ probable congenital hypothyroidism was 1 in 4400 live births. For the definitel probable groups median age of Guthrie collection was consistently between 6 and 7 days from 1983 onwards but for the whole cohort was later than 10 days in $10.5 \%$. Median age of notification fell from 14 days in 1980 to 11 days in 1993. Median age of starting treatment ranged between 11 and 15 days from 1983 onwards. Treatment was delayed in four cases, three due to failed or late Guthrie card submission. Of 149 children with definite/ probable congenital hypothyroidism who were of school age, educational status was ascertained in 139 (93\%). Only two children $(1.4 \%)$ were attending special school, one of whom was known to have mild hypothyroidism. Sixteen children (11.5\%) were receiving extra help in mainstream education compared with $18 \%$ of control children in the Scottish very low birth weight study.

Conclusion-The current screening programme is working well, but efficiency could be increased by earlier and more reliable Guthrie collection. A substantial proportion of children picked up on the screening programme have a transient rise in TSH rather than true congenital hypothyroidism. The incidence of special education and learning support in Scottish children with congenital hypothyroidism appears to be no different to that of the general population.

(Arch Dis Child 1997;76:411-415)

Keywords: congenital hypothyroidism; neonatal screening; educational outcome

Neonatal screening for congenital hypothyroidism became established in North America and Western Europe during the late 1970s and early $80 \mathrm{~s}^{1-4}$ The screening programme for Scotland began in the second half of $1979^{5}$ and the purpose of this paper is to look at its efficiency in terms of ages at Guthrie card collection, notification of raised thyroid stimulating hormone (TSH) by the screening laboratory, and initiation of treatment (where appropriate). We have assessed outcome by looking at the eventual diagnostic assignment of children found to have raised $\mathrm{TSH}$ on routine screening. We have also examined the educational status of children with definite or probable congenital hypothyroidism, since this relates to age of notification and start of treatment, although outcome is also affected by severity of hypothyroidism at diagnosis ${ }^{6}$ and the adequacy of subsequent treatment. ${ }^{7}$

\section{Methods}

SCREENING PROGRAMME

Figure 1 shows the reporting and recall procedures adopted by the screening laboratory at Stobhill. During the 15 year period the cut off for immediate notification changed from 50 to $40 \mathrm{mU} / 1$, and for recall from 25 to $15 \mathrm{mU} / 1$.

TSH ASSAY

Between 1979 and 1982 TSH was measured by a radiolabelled anti-TSH method using a commercial kit produced by Corning. This was replaced by an in-house method between 1982 and 1989, using radiolabelled polyclonal antiTSH. During this period there were several modifications of the radiolabel following a particularly high recall rate in 1985 and 1986. From May 1989 onwards a commercial kit has been employed using a monoclonal antibody coated tube IRMA (IDS).

\section{DATABASE}

Between 1990 and 1991 a database was developed by MR, who devised a proforma comprising basic information (name, date of birth, address, change of address, paediatrician, and 


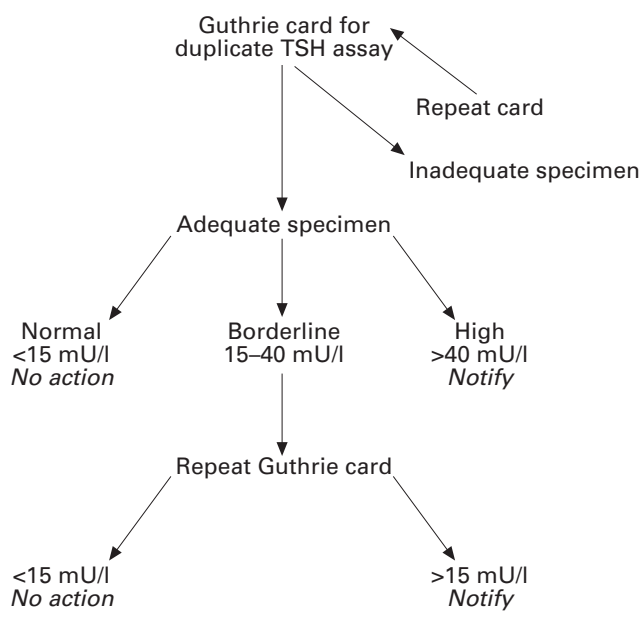

Figure 1 Protocol for the notification of infants with raised TSH on Guthrie card screening.

general practitioner), birth and family data (including maternal and paternal details, birth weight, gestation, presence of congenital anomalies including cardiac disease, presence of dysmorphic features, and details of neonatal intensive care), neonatal TSH screening data (including age of Guthrie card, age of notification, and TSH value), diagnostic investigations including thyroid scan, classification of type of hypothyroidism, and data on growth, thyroxine dosage, and venous thyroxine (T4) and TSH values. In 1992 all data were entered onto a Paradox version 3.5 database. Information on all patients was gathered with permission from the paediatricians within and outside Scotland who were caring for the children detected on the screening programme. From 1992 onwards the database has been increased and updated on a prospective basis by submitting proformas to paediatricians looking after new cases and asking for annual updates on existing patients. Scottish paediatricians were also asked if they knew of any child presenting with hypothyroidism before 5 years of age in whom no abnormality had been found on Guthrie screening.

ASSIGNMENT TO DIAGNOSTIC CATEGORIES Since thyroid scanning of babies identified on neonatal screening is not universal in Scotland, especially in acutely ill babies and/or babies with multiple problems, we devised criteria for definite hypothyroidism, probable hypothyroidism, thyroid status uncertain, and transient $\mathrm{TSH}$ elevation as follows:

Definite congenital hypothyroidism

One or more of the following:

- Initial venous $\mathrm{T} 4<60 \mathrm{nmol} / 1$ and $\mathrm{TSH}>$ $40 \mathrm{mU} / 1$ in an otherwise well term baby.

- Abnormal thyroid scan.

- Venous TSH > $40 \mathrm{mU} / 1$ in sibling of child known to have dyshormonogenesis.

- $\mathrm{TSH}>10 \mathrm{mU} / 1$ on treatment after the first year, or $>15 \mathrm{mU} / 1$ following complete withdrawal of treatment.

Probable congenital hypothyroidism

- Definite criteria not met.
- Initial venous T4 $60-100 \mathrm{nmol} / 1$ and TSH $>100 \mathrm{mU} / 1$ in an otherwise well term infant.

Transient TSH elevation

- Guthrie TSH >15 mU/1 but normal T4

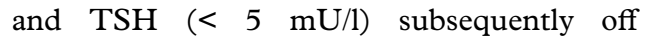
treatment.

\section{Thyroid status uncertain}

- Definite and probable criteria not met.

A child was classified as 'sick' if she/he was receiving assisted ventilation, intravenous fluids, intravenous antibiotics, total parenteral nutrition, or requiring emergency surgery around the time of Guthrie sampling.

\section{EDUCATIONAL STATUS}

In April 1994 the educational status of school age children (born from 1989 onwards) was assessed by sending questionnaires to parents through their paediatricians. The questionnaire simply asked which school year the child was in, whether the child was at normal school with or without special help, at a special school, and whether or not a record of needs had been taken out by the Education Department. The findings of the survey were compared with statistical information on children with special educational needs, kindly provided by $\mathrm{Mr}$ Rogerson in the Education Department of the Scottish Office, and also from control data gathered in 1992/3 in 8 and 9 year old children as part of a Scottish study on school attainment in very low birth weight infants. ${ }^{8}$

\section{Results}

Table 1 gives information on the number of live births and Guthrie tests performed from 1979 to 1993. The excess of tests over births is explained by some infants being tested more than once. Between 1 August 1979 and 31 December 1993, 344 children were found to have raised TSH values and all but one of these was positive on the Guthrie screening programme, the only exception being a girl who was diagnosed clinically as hypothyroid at 42 days, no Guthrie card having been submitted previously. There were three other manifest errors during the study period, with late Guthrie card submission (at 35 and 49 days) in two children and in a third child where Guthrie test had been performed on day 7 but the raised TSH had been missed on the printout, and she was diagnosed clinically at 13 days.

Only one possible false negative case was reported. This was a girl who had a negative Guthrie test on day 9 but presented at 4 years with delayed speech and was manifestly hypothyroid at 7 years. Isotope scanning showed no functioning thyroid tissue and autoantibodies were negative.

\section{ASSIGNMENT TO DIAGNOSTIC CATEGORIES}

Table 2 shows the number of children in each of the four diagnostic categories: definite and probable congenital hypothyroidism, uncertain status, and transient TSH elevation. Eighty eight children were found to have transient TSH elevation. Of these, 22 were given thyrox- 
Table 1 Live births and Guthrie thyroid stimulating hormone (TSH) tests in Scotland between 1979 and 1993, showing the numbers of children with transiently raised TSH and definite/probable (def/prob) congenital hypothyroidism ( $\mathrm{CH}$ ), and the estimated incidence of congenital hypothyroidsim

\begin{tabular}{llllll}
\hline Year & Total live births & No of tests & $\begin{array}{l}\text { Nowith transient } \\
\text { TSH elevation }\end{array}$ & $\begin{array}{l}\text { No with } \\
\text { def/prob CH }\end{array}$ & $\begin{array}{l}\text { Estimated } \\
\text { incidence of } C H\end{array}$ \\
\hline 1979 & 68336 & 10036 & 0 & 5 & - \\
1980 & 68892 & 68784 & 0 & 13 & 5299 \\
1981 & 69054 & 69572 & 0 & 18 & 3836 \\
1982 & 66196 & 66864 & 2 & 12 & 5516 \\
1983 & 65078 & 65137 & 3 & 21 & 3098 \\
1984 & 65106 & 65843 & 8 & 15 & 4340 \\
1985 & 66676 & 67338 & 18 & 9 & 3922 \\
1986 & 65812 & 66187 & 11 & 19 & 3312 \\
1987 & 66241 & 67204 & 5 & 21 & 3152 \\
1988 & 66212 & 66975 & 10 & 22 & 2885 \\
1989 & 63480 & 63827 & 7 & 14 & 3141 \\
1990 & 65973 & 66765 & 10 & 10 & 4787 \\
1991 & 67024 & 67374 & 3 & 17 & 3726 \\
1992 & 65789 & 66225 & 5 & 4 & 378 \\
1993 & 63337 & 66799 & 4 & & \\
\hline
\end{tabular}

Estimated average incidence of congential hypothyroidism: 1 in 4350 live births.

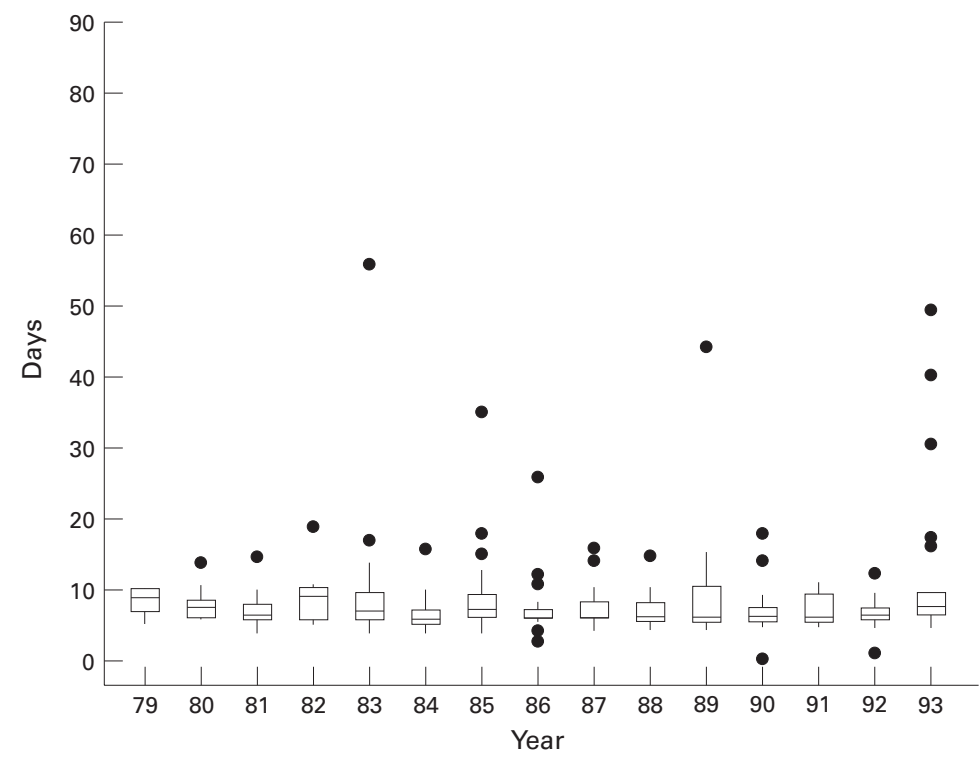

Figure 2 Box and whiskers plot of age at Guthrie collection in infants with raised thyroid stimulating hormone (TSH) in the Scottish hypothyroid screening programme, 1979-93. Median values are represented by the line across the box, outliers by dots.

ine initially, but were subsequently found to have normal thyroid function when treatment was withdrawn. As expected, there was a female preponderance of approximately 2 to 1 in the definite and probable groups, but not in the transient group. The number of premature and/or 'sick' infants was much greater in the transient group.

In the 224 children with definite hypothyroidism, 96 had a thyroid isotope scan and this was of diagnostic value in 91. A specific cause, based on information from family history, clinical examination, thyroid scan, maternal thyroid autoantibody status, necropsy findings (three patients), or various combinations of these was established in 108 children. These were: thyroid ectopia (32), athyreosis (35) and hypoplasia (17), dyshormonogenesis (20), isoimmune thyroiditis (3), and pseudohypoparathyroidism (1). Of the remaining 115 children in whom no cause was established (usually because no thyroid scan had been performed) the diagnosis of definite hypothyroidism was based on $\mathrm{TSH}$ elevation of greater than 10 $\mathrm{mU} / 1$ after the first year in 56 , and/or an initial venous T4 of less than $60 \mathrm{nmol} / 1$ and a TSH of greater than $50 \mathrm{mU} / 1$ in the absence of prematurity or 'sickness' in 84 .

INCIDENCE OF CONGENITAL HYPOTHYROIDISM The annual incidence of true congenital hypothyroidism in Scotland (taking the definite and probable groups together, but excluding the groups where thyroid status was uncertain or the rise in TSH transient) varied between 1 in 2900 and 1 in 7300 live births, with an average incidence of 1 in 4400 (table 1).

EFFICIENCY OF CONGENITAL HYPOTHYROID SCREENING PROGRAMME

Figures 2, 3, and 4 show the age at Guthrie collection, notification, and treatment for the cohort of children between 1979 and 1993 in box plot form, where the bottom of the box is at the lower quartile, the top at the upper quartile, and the median is drawn across the box. Vertical lines represent upper and lower limits with outliers represented as single dots. In figs 3 and 4 the transient/uncertain groups are excluded.

Age at Guthrie collection

Median ages of Guthrie collection were consistently 6-7 days in the definite/probable groups from 1983 onwards but more variable in the uncertain/transient groups, at between 5 and 14 days. Of the 344 infants in the cohort $36(10.5 \%)$ had their first Guthrie test after 10 days of birth -11 from the definite group, five from the uncertain group, and 20 from the transient group.

Age at notification

Of the 235 infants with definite/probable congenital hypothyroidism, only $18(7.7 \%)$ had been clinically detected and treated by the time of notification, which in this group was consistently between 10 and 12 days from 1983 onwards. Again the uncertain/transient groups showed more variation (11-21.5 days), consistent with a combination of later initial sampling and time taken for recall samples.

Table 2 Diagnostic categories and basic information on 344 Scottish infants with raised thyroid stimulating hormone (TSH)

\begin{tabular}{lllll}
\hline & Definite & Probable & Uncertain & Transient \\
\hline No of children (\%) & $224(65.1)$ & $11(3.2)$ & $21(6.1)$ & $88(25.6)$ \\
F:M ratio & $2.2: 1$ & $2: 1$ & $1.9: 1$ & $1: 1$ \\
Birth weight mean (range) & $3.34(1.28$ to 3.52$)$ & $3.48(2.86$ to 4.37$)$ & $3.18(1.23$ to 4.55$)$ & $2.77(0.78$ to 4.32$)$ \\
Preterm & $15(6.7)$ & 0 & $2(9.5)$ & $24(27.3)$ \\
$\begin{array}{l}\text { Deaths } \\
\text { 'Sick' }\end{array}$ & $5(2.2)$ & 0 & $6(28.6)$ & $4(4.5)$ \\
$\begin{array}{l}\text { Total with one or more congential } \\
\quad \text { malformations }\end{array}$ & $16(7.1)$ & 0 & $5(23.8)$ & $33(37.5)$ \\
& $12(5.4)$ & 0 & $6(28.6)$ & $13(14.8)$ \\
\hline
\end{tabular}




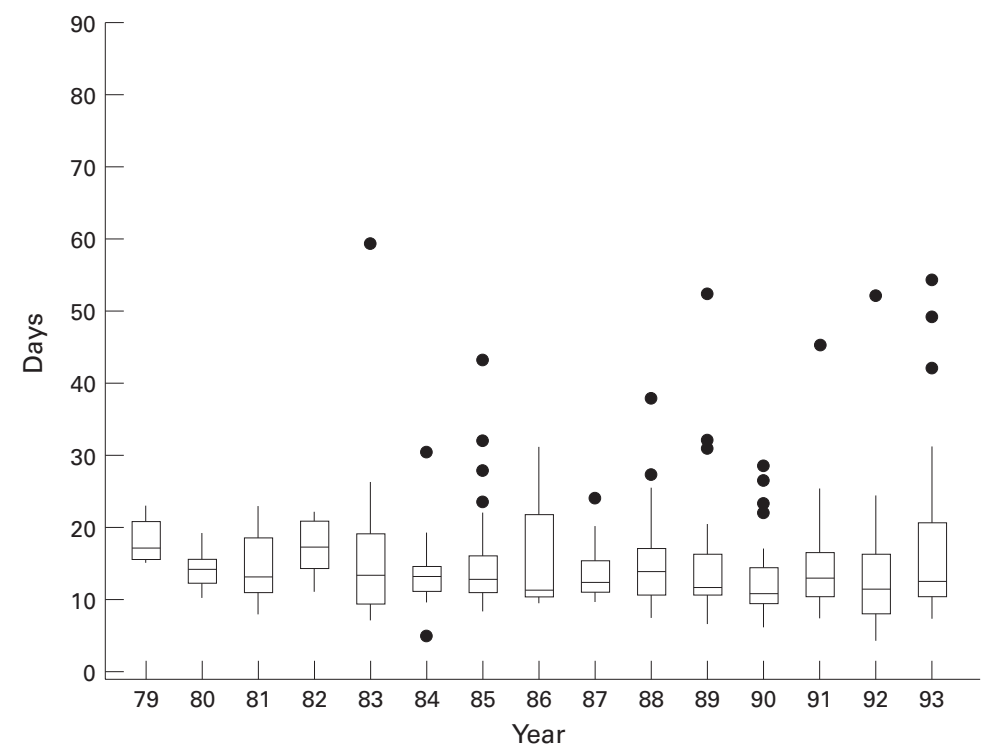

Figure 3 Box and whiskers plot of age at notification in 234 infants with definite/probable congenital hypothyroidism diagnosed in Scotland, 1979-93. Median values are represented by the line across the box, outliers by dots.

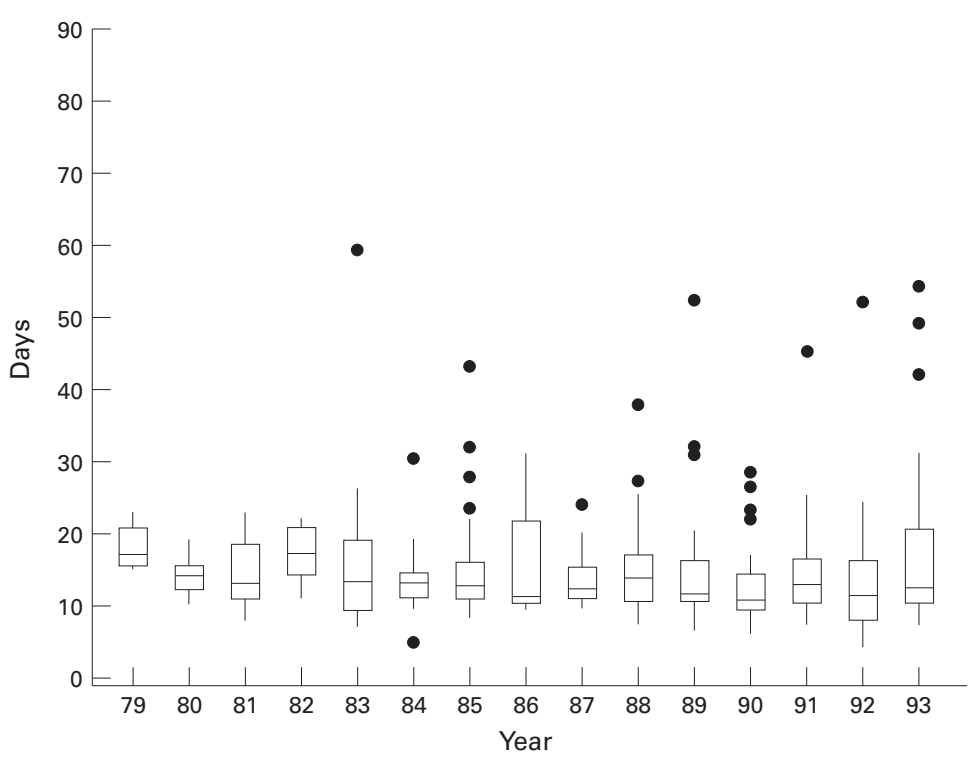

Figure 4 Box and whiskers plot of age at start of treatment in 234 infants with definite/probable congenital hypothyroidism diagnosed in Scotland, 1979-93. Median values are represented by the line across the box, outliers by dots.

Age at starting treatment

Median ages fell from 17.5-21 days before 1983 to 11-15 days thereafter in the definite/ probable groups, with much later median treatment times for the minority $(37 \%)$ of infants in the uncertain/transient groups who actually received treatment. This was attributable to a combination of later notification and clinical uncertainty as to whether treatment was appropriate. During the study period, 45 infants $(13 \%$ of the cohort) started treatment after 20 days -27 from the definite group, five from the uncertain group, and 13 from the transient group.

PATTERN OF TRANSIENT TSH ELEVATION DURING THE STUDY PERIOD

An unusually large number of infants was found to have transient TSH elevation in 1985 and 1986 (table 1), with only four from each year actually receiving treatment. This coincided with a change in radiolabel in the screening laboratory. In 1988 there was a similar peak of transient TSH elevation, with 10 cases reported but only two treated. A further peak in 1990 was associated with a particularly high incidence of prematurity and sickness.

\section{EDUCATIONAL STATUS}

One hundred and forty nine children were of school age in 1994, and information was available on 139 (93\%). Two children (1.4\%) were attending special schools, one of whom had mild dyshormonogenesis with raised TSH but normal thyroxine off treatment. Sixteen children $(11.5 \%)$ were receiving some sort of extra help in mainstream education-12 of 104 in primary school and four of 35 in secondary school. Four children (2.9\%) had had a Record of Needs taken out by the Education Department, of whom two were the children attending special school.

\section{Discussion}

This audit has shown a favourable uptake of neonatal screening and, in those infants with definite/probable hypothyroidism, reasonable median ages of Guthrie sample collection (7 days). However, it is of concern that some infants are still sampled late, particularly those with uncertain classification or transient TSH elevation, in whom there is a much higher incidence of prematurity and sickness (see table 2). ${ }^{9}$ A common reason for late Guthrie card sampling is the belief that the child must be receiving milk for the phenylketonuria test to be valid. However, an infant not receiving milk beyond 5 days of age is likely to be catabolic so that phenylketonuria is unlikely to be missed. Moreover, it is perfectly feasible to submit a Guthrie card on all newborns on day 5 irrespective of gestation or sickness, sending a second sample for repeat phenylalanine estimation once the infant is receiving milk.

The median ages of notification before 1983 (17.5-21 days) are consistent with other reports from that time in the United Kingdom $^{10}$ and North America, ${ }^{11}$ while the current age of notification (10-11 days) and start of treatment (11-15 days) compares favourably with more recent reports from Europe. $^{12}$

Numerous studies have shown small differences in IQ between healthy controls and hypothyroid children detected by neonatal screening. ${ }^{13-17}$ Of particular relevance to our study is the large and detailed psychometric evaluation carried out by Fuggle et al who showed a 7 point difference in IQ between 344 hypothyroid children and 112 controls at 5 years of age. ${ }^{17}$ This group went on to demonstrate a discontinuous relation between IQ and plasma thyroxine concentration at diagnosis, with an apparent threshold at 43 $\mathrm{nmol} / \mathrm{l}^{6}$

In this study we have simply audited the number of children attending special school, and mainstream education with special help. While these indices are extremely crude, it is 
nevertheless of value, when counselling the parents of newly diagnosed infants, to translate the prognosis for intellectual outcome in terms of their child's likely educational requirement. In this study, data were available on 139 children of whom only two were receiving special education. One of these is known to have mild hypothyroidism and his placement is more due to social and emotional problems than to academic difficulties. Sixteen children $(11.5 \%)$ were receiving learning support in mainstream education, of whom two had had a Record of Needs made out by the Education Department, together with the two children at special schools, bringing the total to four $(2.9 \%)$. These data are comparable with information from the Scottish Office on special educational needs in Scottish primary and secondary school pupils. In 1993, $1.3 \%$ of Scottish children were attending special schools and a Record of Needs had been taken out on $1.2 \%$ of children; $6.4 \%$ of children were classified as having learning difficulties. ${ }^{18}$ In the Scottish low birthweight study, Hall et al obtained two age matched controls for each index child in a study of very low birth weight Scottish children aged 8 years. ${ }^{8}$ These investigators found that $18 \%$ of 500 controls and $17 \%$ of another group of 90 controls were receiving learning support; $1 \%$ of the first group and none of the second had had a Record of Needs taken out. No children in either control group were at special schools.

We conclude that the Scottish hypothyroid screening programme is working reasonably well, and our data indicate that the educational needs of affected children are not different from those of the general population. However, efficiency could be increased by earlier and more reliable Guthrie collection. ${ }^{19}$ To rectify this the screening laboratory in Glasgow has recently introduced a quality assurance programme, employing a clinical liaison nurse to monitor the adequacy and timing of blood samples as well as the quality of demographic information provided.
We thank all paediatricians both inside and outside Scotland for heir generosity in contributing to and updating the Scottish Hypothyroid Register. MR was supported by a grant from Greater Glasgow Health Board. TM was supported by a grant from the Clinical Research and Audit Group (CRAG), St Andrew's House, Edinburgh.

1 Illig R, Torresani T, Sobradillo B. Early detection of neonaal hypothyroidism by serial TSH determination in dried tal hypothyroidism by serial TSH determina
blood. Helv Paediatr Acta 1977;32:289-97.

2 Fisher DA, Dussault JH, Foley TPR, et al. Screening for congenital hypothyroidism: results of screening one million North American infants. F Pediatr 1979;94:700-5.

3 Hulse JA, Grant DB, Clayton BE, et al. Population screening for congenital hypothyroidism. BMf 1980;i:675-8.

4 Delange F, Illig R, Rochiccioli P, Brock-Jacobsen B. Progress report 1980 on neonatal thyroid screening in Europe. Acta Paediatr Scand 1981;70:1-2.

5 Sutherland RM, Ratcliffe JG, Kennedy R, Stevenson JS, Patrick MJ, Ferguson-Smith MA. Neonatal screening for Patrick MJ, Ferguson-Smith MA. Neonatal screening for Med 7 1981;26:220-4.

Med f 1981;26:220-4.
6 Tillotsen SL, Fuggle PW, Sith I, Ades AE, Grant DB. Relation between biochemical severity and intelligence in early treated congenital hypothroidism: a threshold effect. $B M \mathcal{F}$ 1995;309:440-5.

7 Mitchell ML, Klein RZ. Motor and cognitive development in children with congenital hypothyroidism. F Pediatr 1995; 126:673.

8 Hall A, McLeod A, Counsell C, Thomson L, Mutch L. School attainment, cognitive ability and motor function in a total Scottish very low birth weight population of 8 a total Scottish very low birth weight population of

years-a controlled study. Dev Med 1995;37:1037-50.
9 Fernhoff PM, Brown AL, Elsas LJ. Congenital hypothyroidism: increased risk of neonatal morbidity results in delayed treatment. Lancet 1987;i:490-1

10 Grant DB, Smith I. Survey of neonatal screening for primary hypothyroidism in England, Wales and Northern Ireland 1982-4. BMF 1988;296:1355-8.

11 New England Hypothyroidism Collaborative. Characteristics of infantile hypothyroidism discovered on neonatal screening. F Pediatr 1984;104:539-44.

12 Toublanc JE. Epidemiological inquiry on congenital hypothyroidism in Europe (1985-1988). Horm Res 1990;34: pothyroi.

13 New England Congenital Hypothyroidism Collaborative. Elementary school performance of children with congenital Elementary school performance of children
hypothyroidism. $\mathcal{F}$ Pediatr 1990;116:27-32.

14 Heyerdahl S, Kase BF, Lie SO. Intellectual development in children with congenital hypothyroidism in relation to recommended treatment. F Pediatr 1991;118:850-7.

15 Toublanc JE, Rives S, Acosta A, Chicaud J. Le développement psychomoteur et intellectuel chez 52 enfants atteints d'hypothroïdie congénitale depistée a la naissance. Arch Fr Pediatr 1990;47:191-5.

16 Rovet JF, Westbrook D-L, Ehrich RM. Neonatal thyroid deficiency: early temperament and cognitive characteristics. F Am Acad Child Psychiatry 1984;23:10-22.

17 Fuggle PW, Grant DB, Smith I, Murphy G. Intelligence, motor skills and behaviour at 5 years in early-treated motor skills and behaviour at 5 years in early-treated

18 Provision of Education for Pupils with Special Education Provision of Education for Pupils with Special Education 9 Tappin DM, Girdwood RWA, Kennedy R, et al. An audit of Tappin DM, Girdwood RWA, Kennedy R, et al. An audit of
infants 'unscreened' by the neonatal screening system in Scotland during 1991. Screening 1995;3:201-7. 